\title{
Resistance to Cell Death in Mucinous Colorectal Cancer-A Review
}

\author{
Emer $\mathrm{O}^{\prime}$ Connell ${ }^{1,2}$, Ian S. Reynolds ${ }^{1,2} \mathbb{D}$, Deborah A. McNamara ${ }^{1,3}$, John P. Burke ${ }^{1}$ and Jochen H. M. Prehn ${ }^{2,4, * \mathbb{D}}$ \\ 1 Department of Colorectal Surgery, Beaumont Hospital, Dublin 9, Ireland; emerpoconnell@rcsi.com (E.O.); \\ ianreynolds@rcsi.ie (I.S.R.); deborahmcnamara@rcsi.ie (D.A.M.); johnburke@rcsi.ie (J.P.B.) \\ 2 Department of Physiology and Medical Physics, Royal College of Surgeons in Ireland, Dublin 2, Ireland \\ 3 Department of Surgery, Royal College of Surgeons in Ireland, Dublin 2, Ireland \\ 4 Centre for Systems Medicine, Royal College of Surgeons in Ireland, Dublin 2, Ireland \\ * Correspondence: Prehn@rcsi.ie
}

check for updates

Citation: O'Connell, E.;

Reynolds, I.S.; McNamara, D.A.;

Burke, J.P.; Prehn, J.H.M. Resistance to Cell Death in Mucinous Colorectal Cancer-A Review. Cancers 2021, 13, 1389. https://doi.org/10.3390/ cancers13061389

Academic Editor: Olivier Cuvillier

Received: 2 February 2021

Accepted: 10 March 2021

Published: 19 March 2021

Publisher's Note: MDPI stays neutral with regard to jurisdictional claims in published maps and institutional affiliations.

Copyright: (c) 2021 by the authors. Licensee MDPI, Basel, Switzerland. This article is an open access article distributed under the terms and conditions of the Creative Commons Attribution (CC BY) license (https:// creativecommons.org/licenses/by/ $4.0 /)$.
Simple Summary: Mucinous colorectal cancer is characterised by abundant mucin glycoprotein production and is associated with resistance to chemotherapy-based treatments. This review outlines mechanisms for cell death resistance present in mucinous colorectal cancer including glycoprotein interactions with cell survival and cell apoptotic pathways. Further mechanisms are explored, including alterations in the expression of chemotherapy metabolism and resistance genes. This review identifies directions for future investigation of mucinous colorectal cancer and novel treatment strategies.

Abstract: Mucinous colorectal cancer (CRC) is estimated to occur in approximately 10-15\% of CRC cases and is characterized by abundant extracellular mucin. Mucinous CRC is frequently associated with resistance to apoptosis. Inferior prognosis is observed in mucinous CRC, particularly in rectal cancer and metastatic cases. Mucins are heavily glycosylated secretory or transmembrane proteins that participate in protection of the colonic epithelium. MUC2 overexpression is a hallmark of mucinous CRCs. Mucinous CRC is associated with KRAS and BRAF mutation, microsatellite instability and the CPG island methylator phenotype. Mutations of the APC gene and p53 mutations which are characteristic non-mucinous colorectal adenocarcinoma are less common in mucinous CRC. Both physical and anti-apoptotic properties of mucin provide mechanisms for resistance to cell death. Mucin glycoproteins are associated with decreased expression of pro-apoptotic proteins, increased expression of anti-apoptotic proteins and increased cell survival signaling. The role for BCL-2 proteins, including BCL- $\mathrm{X}_{\mathrm{L}}$, in preventing apoptosis in mucinous CRC has been explored to a limited extent. Additional mechanisms opposing cell death include altered death receptor expression and altered mutation rates in genes responsible for chemotherapy resistance. The roles of alternate cell death programs including necroptosis and pyroptosis are not well understood in mucinous CRC. While the presence of MUC2 is associated with an immunosuppressive environment, the tumor immune environment of mucinous CRC and the role of immune-mediated tumor cell death likewise require further investigation. Improved understanding of cell death mechanisms in mucinous CRC may allow modification of currently used regimens and facilitate targeted treatment.

Keywords: mucin; colorectal; apoptosis; chemo-resistance

\section{Introduction}

Colorectal cancer (CRC) is a major health challenge: the global burden of CRC is expected to increase by $60 \%$ to more than 2.2 million new cases and 1.1 million deaths by 2030 [1]. Mucinous CRC is estimated to occur in approximately 10-15\% of CRC cases and is characterized by abundant extracellular mucin that comprise of at least $50 \%$ of the tumor volume [2] (Figure 1). Mucinous CRCs occur more frequently in the proximal colon, occur at a younger age, and have a slight female predominance compared to nonmucinous CRC [3-5]. Mucinous CRCs tend to be larger than non-mucinous CRCs and are more commonly diagnosed at an advanced stage $[4,5]$. The molecular characteristics 
of mucinous CRC suggest that mucinous tumors develop and progress through different molecular pathways compared with non-mucinous CRCs.

(a)

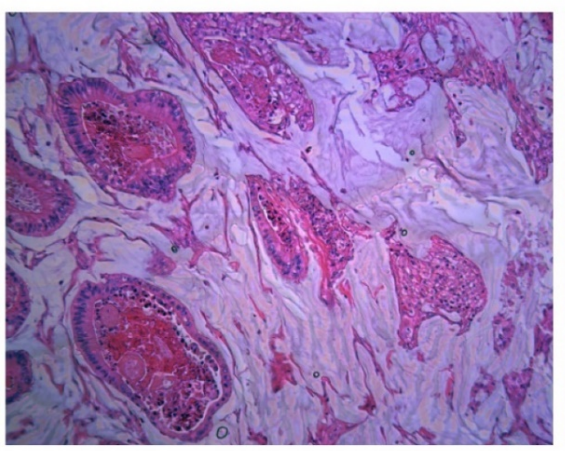

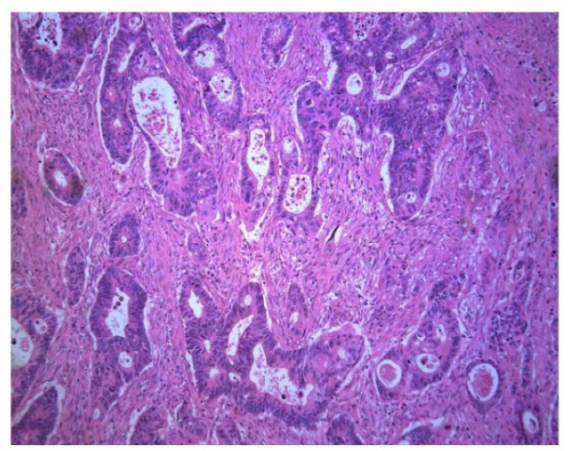

Figure 1. Representative histological slides of: (a) mucinous colorectal adenocarcinoma displaying abundant extracellular mucin in a 61 year old male patient with a pT4N2 mucinous rectal tumor. (b) Non-mucinous colorectal adenocarcinoma in a 67 year old female patient with a pT3N1 rectal tumor. H\&E-stained section, $10 \times$ magnification, imaged with Leica DM 4000B microscope (Leica Microsystems, Mannheim, Germany).

\section{Molecular Characteristics of Mucinous Colorectal Cancer}

Sporadic CRC develops through a well-recognized pathway in approximately $85 \%$ of cases with accumulation of mutations in oncogenes and tumor suppressor genes leading to chromosomal instability (CIN). Mutations of the APC gene which are characteristic of chromosomal instability are less common in mucinous CRC [6]. p53 mutations are common in tumors with chromosomal instability but less common in mucinous CRC [7]. Alternate pathways for CRC tumorigenesis are described including promotor methylation of the MLH1 gene resulting in sporadic microsatellite instability [8], and also aberrant methylation and silencing of tumor suppressor genes termed epigenetic instability [9]. A meta-analysis of 46 studies describing 17,746 patients by Reynolds et al. in 2019 clarified molecular associations of mucinous CRC [10]. Mucinous CRC is associated positively with KRAS and $B R A F$ mutation, microsatellite instability (MSI) and the CpG island methylator phenotype (CIMP) and negatively associated with altered $p 53$ expression [10]. BRAF and KRAS are both components of the RAS /MAPK pathway, and activation of this pathway promotes cell division and reduces cell apoptosis [11]. Mutations in KRAS lead to an epidermal growth factor receptor-independent disturbance of the RAS/RAF/MAPK pathway, which regulates cell proliferation and survival and is a prognostic factor in CRC [12]. BRAF mutations are commonly reported in patients with mucinous CRC and are associated with an infiltrative pattern of tumor growth [12,13]. In addition to mutations in KRAS and $B R A F$ affecting the RAS/RAF/MAPK pathway, increased mutations are also reported in the PI3K/AKT pathways in patients with mucinous CRC [12]. Aberrations in the phosphoinositide 3-kinase (PI3K) signaling pathway play a key role in the pathogenesis of numerous cancers by altering cellular growth, metabolism, proliferation, and apoptosis. Leystra et al. demonstrated in a mouse model that expression of a dominantly active form of PI3K protein results in the development of mucinous colon cancers [14]. MSI is observed at a higher frequency in mucinous CRC compared to non-mucinous CRC. Likewise, Lynch syndrome (LS)-associated CRCs have a high rate of mucinous histology; approximately $22-40 \%$ of LS-associated CRCs are mucinous [15]. These finding substantiate the concept of an alternative oncogenic mechanism leading to mucinous CRC tumorigenesis, different from the classic adenoma-carcinoma sequence [12].

\section{Expression of Mucins in Mucinous Colorectal Cancer}

Mucins are heavily glycosylated secretory or transmembrane proteins that participate in protection of the colonic epithelium and limit inflammatory responses at the interface 
with the colonic lumen [16]. The secreted mucins include MUC2, MUC5AC, MUC5B and MUC6 and form a mucous gel which lines epithelial surfaces [16]. The transmembrane mucins include MUC1, MUC4, MUC13 and MUC16 [16]. These mucins span the cell membrane allowing external glycosylated structures to contribute to the mucous layer and transmembrane domains to interact with intracellular processes. MUC2 is the major component of the two layers of intestinal mucus and is expressed in the healthy colonic epithelium [17]. MUC2 production is increased in the goblet cells of the proximal colon [18], a site where mucinous CRCs are observed with greater frequency. In addition, the expression of MUC5AC which is located on the same chromosome as MUC2 is increased in mucinous CRC compared to non-mucinous CRC $[19,20]$. The presence of MUC2 and/or MUC5AC in colorectal mucinous adenocarcinoma has been shown to be associated with proximal (rightsided) CRC location [21]. MUC2 overexpression is a hallmark of mucinous CRCs [11,12,22]. In contrast, expression of MUC2 is generally decreased in non-mucinous CRC [22]. Loss of MUC2 expression is associated with increased proliferation of intestinal epithelial cells in response to mucosal inflammation [23]. The inflammation and tumor suppression role of MUC2 may appear paradoxical when it is observed that MUC2 expression is increased in mucinous CRC. It is suggested that MUC2 overexpression in cancer may reflect the mucin forming nature of the cancer's cells rather than the intrinsic action of mucin [16]. Additionally, mucin expression may be modified by epigenetic mechanisms in cancers or mucin production may be used as an immune evasion mechanism by cancer cells by masking the cell surface from immune surveillance [16] (see Table 1).

Expression of MUC2 is regulated by a number of factors in the colonic epithelium. Analysis of mucin-producing cell lines by Okudaira et al. demonstrated that methylation of the MUC2 gene promotor was significantly lower in mucinous CRC lines compared to non-mucinous and correlated with mucin protein expression [24]. Loss of functional p53 is responsible for downregulation of MUC2 expression [25]. MUC2 expression is transcriptionally regulated by $p 53$ protein in several cell lines [26]. Regulation of MUC2 by p53 is consistent with the observation of reduced $p 53$ mutations in mucinous carcinomas, where MUC2 expression is increased [25]. In contrast, high rates of p53 mutation and low expression of MUC2 are observed in non-mucinous CRC [26]. Additionally, the mitogen-activated protein kinase (MAPK) signaling pathway is known to regulate MUC2 gene transcription [27]. MAPK signaling is upregulated in the setting of $K R A S$ mutation and in the setting of chronic inflammation, both of which are common features of mucinous cancer [28].

Table 1. Mechanisms for resistance to cell death in mucinous colorectal cancer (CRC).

\begin{tabular}{|c|c|c|}
\hline Mechanism & Effect & Reference \\
\hline \multirow{2}{*}{ Physical tumor structure } & Mucin barrier occluding cells & \multirow{2}{*}{ 「29] } \\
\hline & Compressive effect of mucin & \\
\hline \multirow[t]{7}{*}{ Mucin glycoproteins } & Inhibition of mitochondrial apoptotic signaling & [30-32] \\
\hline & Inhibition of death receptor apoptotic signaling. & [33-35] \\
\hline & Downregulation of $p 53$ & {$[36,37]$} \\
\hline & Activation of JNK1 & \\
\hline & Activation of PI3K/Akt pathway & \\
\hline & Activation of MAPK pathway & \\
\hline & Activation of NF-кB pathway & \\
\hline \multirow[t]{3}{*}{$\mathrm{BCL}-2$ proteins } & Increased expression of BCL- $\mathrm{X}_{\mathrm{L}}$ & {$[31,37,38]$} \\
\hline & Bax G(8) frameshift mutation & [39] \\
\hline & Increased Livin (IAP) expression & \\
\hline \multirow[t]{2}{*}{ Death receptors } & Reduced Fas ligand expression & {$[40,41]$} \\
\hline & Reduced DR4 expression & \\
\hline \multirow[t]{2}{*}{ Chemo-resistance genes } & Overexpression of TYMS & {$[42,43]$} \\
\hline & Altered mutation rate of genes responsible for chemotherapy metabolism & \\
\hline $\begin{array}{l}\text { Tumor immune } \\
\text { microenvironment }\end{array}$ & Adhesion ligands and suppressive cytokines inhibiting immune cell activity & [44] \\
\hline
\end{tabular}




\section{Acellular Mucin Pools Following Neoadjuvant Chemoradiotherapy}

The presence of mucin pools in resection specimens with complete pathological response (pCR) has been observed following neoadjuvant treatment of rectal cancers with non-mucinous features prior to treatment. The significance of acellular mucins pools in the setting of complete tumor regression and their implications for tumor staging and prognosis have been evaluated in the literature. Comparison of survival outcomes between cases of $\mathrm{pCR}$ with or without mucin pools demonstrated no survival difference in a number of retrospective studies [45-48]. Mucin pools were found in proctectomy specimens in $12 \%(12 / 297)$ of patients following long course neoadjuvant chemoradiotherapy (NACRT) in a retrospective analysis by Reynold's et al. [49]. The presence of mucin pools was associated with $\mathrm{pCR}$ and improved overall survival (OS), suggesting they may represent a treatment response. Analysis of 118 cases of locally advanced rectal cancer (LARC) achieving $\mathrm{pCR}$ after NACRT were retrospectively reviewed by Sun et al. Acellular mucin pools were observed in $27 \%$ and no difference in 5-year OS was observed in those with or without mucin pools. However, in univariate analysis, patients with mucin pools had increased risk of distant metastases, although this observation was not maintained on multivariate analysis [50]. More recently, Zhang et al. evaluated 117 locally advanced rectal cancers achieving pCR after NACRT. Acellular mucin pools were identified in $23 \%$. In multivariate analysis, the presence of acellular mucin pools showed no prognostic impact on OS or disease-free survival (DFS) [51]. Overall, the literature suggests that the presence of acellular mucin pools in post-treatment $\mathrm{PCR}$ does not appear to be a significant prognostic factor and may be indicative of tumor response to therapy. The presence of residual tumor cells in mucin pools requires further prognostic clarification and underlines the need for careful pathological evaluation. Under current AJCC 8th edition guidelines, acellular mucin following neoadjuvant treatment is advised to represent eradicated tumor and should not upstage tumors [52].

\section{Apoptosis and Other Cell Death Signaling Pathways in Mucinous Colorectal Cancer}

BCL-2 family proteins are key for the activation of the mitochondrial or intrinsic apoptosis pathway [30]. The role of the BCL-2 family of proteins has been explored to a limited extent in mucinous CRC. The importance of BCL-2 and its family members in cell survival, differentiation, and oncogenesis has been demonstrated extensively in multiple cancers [31]. Dysregulation of BCL-2 proteins occurs during tumor development and is responsible for cellular resistance to chemotherapy treatments [53]. BCL-2 family proteins are described based on their pro-apoptotic or anti-apoptotic function [40]. Early immunohistochemical analysis of mucinous and non-mucinous CRCs by Zhang et al. demonstrated no association between mucinous histology and BCL-2 staining [41]. A similar analysis by Contu et al. observed no association between BCL-2 expression and mucinous histology in rectal cancers [32]. However, recent IHC study by Bhardwaj et al. identified BCL-2 positivity more frequently in non-mucinous colorectal tumors compared to mucinous [54]. In addition, a large proportion of colorectal tumors with microsatellite instability contain frameshift mutations in the Bax gene, a major apoptosis effector. Analysis of Bax mutations and apoptotic indices in colorectal tumors showed that mutations in Bax were associated with proximal, poorly differentiated and mucinous CRC [55].

Caspases 3 and 7 are activated downstream of mitochondrial permeabilization during the intrinsic apoptosis pathway, but may also be activated through death receptors and other intracellular caspase activating platforms [30]. Inhibitor of apoptosis proteins (IAPs) are natural inhibitors of caspases [30]. BIRC7/Livin is an inhibitor of apoptosis protein (IAP) associated with suppression of apoptosis in CRC [56]. Faruk et al. recently explored the expression of proteins relevant for apoptosis including p53, BCL2, Livin and Annexin $\mathrm{V}$ in mucinous and non-mucinous CRC [57]. Tumor samples from 23 patients with mucinous CRC were compared with 69 non-mucinous CRCs with neoadjuvant FOLFOX chemotherapy administered in a subset of the cohort. Livin expression was significantly lower in mucinous CRC at baseline compared to non-mucinous CRC. A significant in- 
crease in the expression of Livin was observed in mucinous CRC following treatment with FOLFOX chemotherapy while FOLFOX suppressed Livin expression in non-mucinous CRC. A significant increase in Annexin V was observed in FOLFOX treated non-mucinous CRC compared to FOLFOX treated mucinous CRC indicating increased apoptotic activity. No significant difference was observed between the expression of p53 or BCL-2 in mucinous versus non-mucinous CRC. Systematic studies that analyze the entire framework of apoptosis signaling pathways in mucinous CRC are now warranted.

In addition to apoptotic programmed cell death, alternate cell death mechanisms including necroptosis and pyroptosis are known to occur CRC and in patients with inflammatory bowel disease (IBD) [33]. However, the role for necroptosis and pyroptosis in cell death requires exploration in mucinous CRC.

\section{Mechanisms of Apoptosis Resistance in Mucinous Colorectal Cancer: Studies Exploring the Biological Functions of Individual Mucin Glycoproteins 6.1. MUC1 Glycoprotein}

Mucin glycoproteins are associated with the inhibition of apoptosis in both in vitro and in vivo models of CRC (see Figure 2). MUC1 is normally expressed on the apical borders of epithelial cells but is often overexpressed on the surface of cancer cells. Investigation in an in vitro colon cancer model used confocal microscopy to demonstrate that the MUC1C-terminal intracellular domain (MUC1-C) localizes to the mitochondria [34]. Resistance to chemotherapy is frequently associated with defective intrinsic apoptosis and impaired release of mitochondrial cytochrome c. Release of cytochrome $\mathrm{c}$ in response to cisplatin was compared between colon cancer cells stably transfected with MUC1 versus empty vector cells. Expression of MUC1 significantly reduced cytochrome c release [34]. In addition, the release of SMAC/Diablo was attenuated in MUC1 expressing cells. Likewise, MUC1 attenuated activation of caspase 3 in response to cisplatin [34]. In vivo MUC1-expressing tumors had limited response to cisplatin treatment. Knockdown of MUC1 increased sensitivity to genotoxic drugs [34]. Further in vitro research from this group, although performed in a non-CRC model demonstrated further mechanisms for cell survival and apoptosis inhibition related to MUC1 [58]. MUC1 expression was found to influence PI3K-Akt signaling with increased in phosphor-Akt in MUC1 transfected cells. In addition, BCL- $\mathrm{X}_{\mathrm{L}}$ expression was increased in MUC1 expressing cells. Treatment of MUC1 transfected and empty vector cells with an antimetabolite demonstrated decreased mitochondrial membrane potential in empty vector cells but not in MUC1 expressing cells. Activation of caspase 9 and caspase 3 cleavage activity was reduced in MUC1 expressing cells. The expression of BCL- $\mathrm{X}_{\mathrm{L}}$ was not altered by use of a PI3K inhibitor, indicating BCL- $\mathrm{X}_{\mathrm{L}}$ expression was independent of PI3K signalling [58].

Agata and colleagues demonstrated a critical role for MUC1 in response to death receptor signalling [35]. In vitro studies in mixed cell lines found that the MUC1 cytoplasmic domain binds directly to the caspase 8 p18 fragment and the FADD as a response to death receptor signalling. MUC1 was found to compete with caspase- 8 for binding to FADD and blocked recruitment of caspase- 8 to the death inducing signalling complex. This interaction could underlie impaired death receptor sginalling in malignant cells with overexpression of MUC1. This study supports the earlier work from this group who demonstrated that MUC1 blocked TRAIL-induced apoptosis of CRC cells [34]. Interestingly, resistance to death receptor signaling has been demonstrated in mucinous CRC tumor specimens. Analysis of CRC cases by Sheehan et al. indicated identified lower FasL expression in mucinous adenocarcinomas [36]. In addition, a small series from Koornstra et al. identified that DR4 expression was absent in sporadic mucinous MSI-high CRCs [59].

Within an in vitro CRC model, Chen et al. demonstrated that MUC1 reduces apoptosis to DNA damage through direct binding to JNK1 [37]. JNK (c-Jun N terminal kinase) is a member of the MAPK family. Treatment of MUC1-expressing colon cancer cells with cisplatin or doxorubicin induced phosphorylation of JNK1 and cJUN, with phosphorylation enhanced by ectopic expression of MUC1. MUC1 expression was found to significantly 
reduce PARP cleavage, an effect reversed in the presence of JNK inhibitor, indicating a critical role for JNK activation in MUC1 apoptosis resistance.

(a)

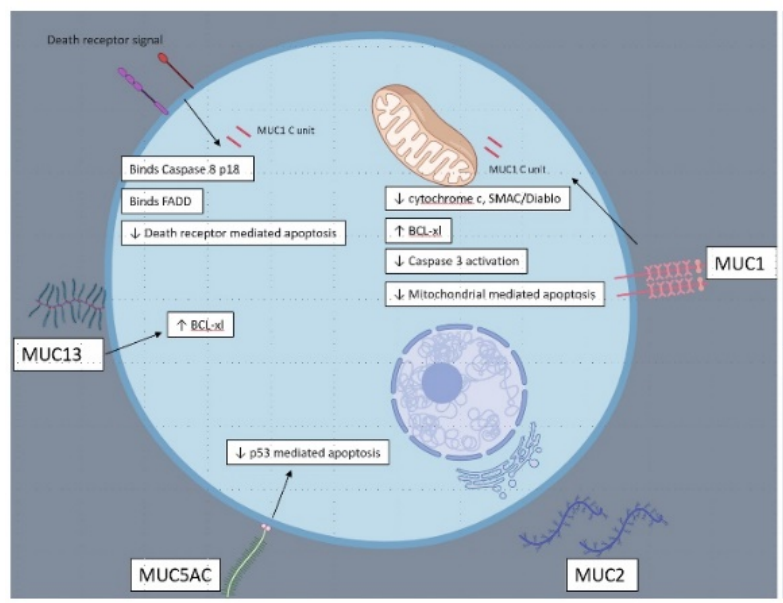

(b)

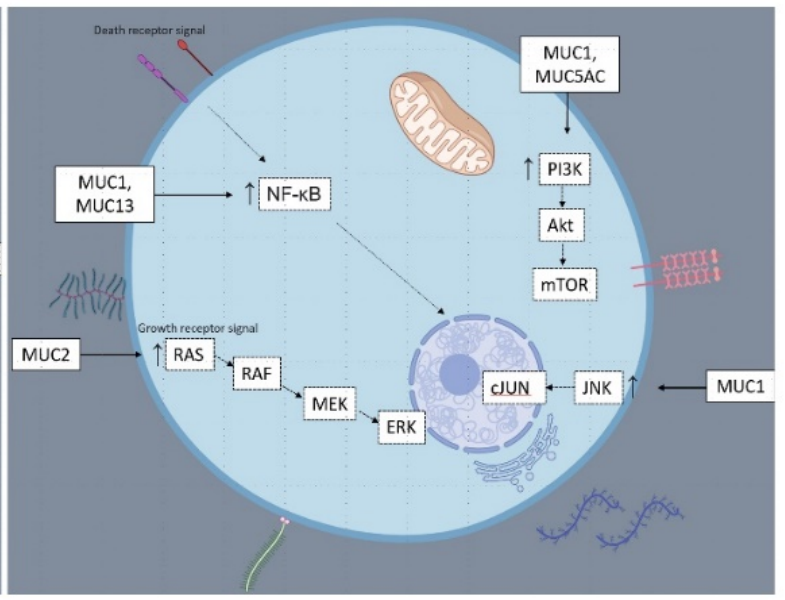

Figure 2. (a) Interaction of mucin glycoproteins with apoptosis proteins in colorectal cancer cells. (b) Cell survival mechanisms altered by expression of mucin glycoproteins in colorectal cancer cells.

\subsection{MUC2 Glycoprotein}

Attenuation of MUC2 expression was found to significantly increase apoptosis in a mucinous colon cell line and a patient-derived xenograft model of mucinous peritoneal carcinomatosis in a study by Dilly et al. [60]. This group further explored treatments involving MUC2 attenuation to induce apoptotic cell death in mucinous CRC. The endoplasmic reticulum (ER) is a site for synthesis and protein folding including production of MUC2 [61]. Disruption of normal protein processing can cause overwhelming ER stress and trigger the unfolded protein response (UPR) while persistent ER stress will trigger cell death pathways [62]. Dilly and colleagues have hypothesized that mucinous CRC with high MUC2 production would be vulnerable to ER stress and ER-stress associated cell death [61]. Authors have demonstrated that basal markers of endoplasmic reticulum stress (ERS) are higher in mucinous tumors in in vitro and tumor explant models [61]. Treatment in vitro with ERS augmentation by orlistat and celecoxib induced apoptosis. Apoptosis was detected by TUNEL assay and detection of pro-apoptotic proteins BIM, NOXA, PUMA and activated cleaved caspase 3 and cleaved PARP by Western blotting. Changes in mitochondrial membrane potential were detected by fluorescent imaging and confirmed activation of intrinsic apoptosis in addition to detection of cleaved caspase 9 and 3 but not caspase 8 . Reduced cleaved caspase 3 and cleaved PARP was detected in cells with knockdown of the UPR protein CHOP following drug treatment implying an ERS dependent apoptotic process. In addition, mucinous tumor growth in vivo was reduced and ERS stress and apoptosis increased by treatment with orlistat and celecoxib [61].

Additional work from Dilly et al. has utilized a similar in vitro model of mucinous CRC based on a KRAS mutant LS174T MUC2 producing cell line. Mucinous CRC are associated with KRAS mutations, resulting in downstream activation of MAPK and PI3K signaling pathways [12]. MAPK and PI3K signaling has been demonstrated to protect some cancers from ERS cell death [63], leading Dilly et al. to hypothesize that MEK and PI3K inhibition may inhibit survival pathways and sensitize cells to ERS induced apoptosis [64]. Co-treatment of mucinous colon cancer cells with a MEK inhibitor and PI3K inhibitor induced apoptotic cell death as demonstrated by Annexin/PI staining. Dual drug treatment reduced phosphorylated-ERK and phosphorylated-Akt protein levels consistent with MAPK/PI3K signaling inhibition. Expression of PUMA, cleaved caspases 9, cleaved caspase 3 (but not caspase 8), and cleaved PARP increased following dual drug therapy consistent with intrinsic apoptosis signaling. TUNEL assay demonstrated 
increased apoptosis in tumor explants treated with dual MEK and PI3K inhibition. Dual drug treatment likewise reduced MUC2 secretion in vitro and in explant tissue, which was found to be mediated by significantly reduced FASN expression, an enzyme necessary for MUC2 N-terminal palmitoylation and secretion. The growth of patient-derived xenografts was inhibited by dual MEK and PI3K inhibition [64].

\subsection{MUC5AC Glycoprotein}

In a study by Zhu et al. [65], the expression of MUC5AC was found to be significantly elevated in colon cancer tissues when compared with the corresponding para-cancerous tissues in the clinical setting. In vitro assays showed that inhibition of MUC5AC by siRNA reduced colony formation of the SW620 cell line. Authors transfected a colon cancer cell line with siRNA-control or siRNA-MUC5AC and assessed apoptosis and the cell cycle by flow cytometry. The apoptosis rate was significantly enhanced in MUC5AC knockdown cells. The cell cycle was found to be arrested in G1, but siRNA-control had no effects on the apoptosis and cell cycle of SW620, indicating decreased cell vitality and colony formation were attributed to the MUC5AC-related apoptosis and cell cycle arrest [65]. Upregulation of MUC5AC in CRC cells has recently been confirmed as a mechanism for resistance to 5-FU and oxaliplatin chemotherapy through down-regulation of p53 and up-regulation of $\beta$-catenin [66]. CD44 is a transmembrane glycoprotein involved in several cellular processes like growth and invasion through Src signaling [67]. Pothuraju et al. observed co-localization of MUC5AC and CD44 by immunoprecipitation and confocal microscopy in CRC [66]. Knockdown of MUC5AC decreased cell survival markers including phosphorylated AKT and phosphorylated Src and increased pro-apoptotic cleaved PARP and cleaved-caspase 9. Knockdown of CD44 also decreased expression of Src and AKT. Combination 5FU and oxaliplatin chemotherapy was found to increase MUC5AC expression in a dose-dependent manner in CRC cell lines and cells expressing MUC5AC had greater viability when compared to MUC5AC knockout cells. MUC5AC knockout cells treated with 5FU had higher rates of cell cycle arrest. In addition, p53 and p21 expression was increased while Chk1, which mediates p53 activation was reduced. Authors observed that 5FU treatment caused reduced Chk1, leading to cell cycle arrest and subsequent activation of $p 53$ to induce apoptosis. In addition, 5FU upregulated the Wnt ligand coreceptor Lrp6 which increased expression of $\beta$-catenin and its target gene CD44 with authors concluding that MUC5AC permits 5FU resistance through the $\beta$-catenin/p53/p21 axis [66].

\subsection{MUC13 Glycoprotein}

Western blot analysis of MUC13 overexpressing cells by Gupta et al. noted that the expression of the anti-apoptotic protein was influenced by MUC13 expression [38]. Sheng et al. explored mechanisms of cell death resistance related to MUC13 expression [68]. In vivo study in mice demonstrated increased intestinal apoptosis in response to DSS exposure in MUC13 knockout mice. In addition, colon cells treated with MUC13 siRNA were more susceptible to apoptosis in response to DSS, UV irradiation and TRAIL [39]. This group subsequently explored expression of regulators of apoptosis and cell death- the BCL2 family and NF-KB signalling [68]. In an in vitro CRC model, silencing of MUC13 decreased mRNA expression of the antiapoptotic gene BCL- $\mathrm{X}_{\mathrm{L}}$. BCL- $\mathrm{X}_{\mathrm{L}}$ is regulated by NF-kB p65 signalling. Combination of MUC13 knockdown and 5FU chemotherapy caused tumor regression in a CRC xenograft model. Similar to their in vitro findings, siRNA knockdown of MUC13 reduced total NF-kB p65 protein and reduced BCL- $\mathrm{X}_{\mathrm{L}}$ expression in tumor cells. Interestingly, immunohistochemical staining of colorectal tumors by Evertsson et al. identified association between mucinous histology and NF-кB expression [69].

\section{Chemotherapy Drug Metabolism and Resistance in Mucinous Colorectal Cancer}

Resistance to commonly used chemotherapeutic agents for CRC has been evaluated in mucinous CRC and was found to involve genes responsible for chemotherapy drug metabolism within cancer cells. The expression of recognized drug metabolism genes was 
compared between 21 patients with mucinous CRC and 30 patients with non-mucinous CRC by Glasgow et al. Mucinous tumors were found to significantly overexpress thymidylate synthase (TYMS) and glutathione S-transferase pi (GSTP1) genes, but no significant difference was noted between the expression of other drug related genes in the study cohort [42]. A recent analysis of The Cancer Genome Atlas (TCGA) dataset identified significant differences in the simple somatic mutation (SSM) rate and copy number variation $(\mathrm{CNV})$ rate in genes with recognized roles in chemotherapy drug resistance in mucinous and non-mucinous CRC [43]. One gene associated with 5-FU resistance, thymidine phosphorylase (TYMP), was found to have an SSM rate of $5.97 \%$ in mucinous tumors compared with only $1.08 \%$ in non-mucinous tumors. Two genes associated with oxaliplatin resistance were found to be mutated at greater frequencies in the mucinous group when compared with the non-mucinous group. ATPase copper transporting beta (ATP7B) was mutated in $8.96 \%$ of mucinous tumors compared with only $3.45 \%$ of non-mucinous tumors. Similarly, SRSF protein kinase 1 (SRPK1) was mutated in $10.45 \%$ of mucinous tumors compared with only $3.23 \%$ of non-mucinous tumors. Two irinotecan resistance-associated genes were mutated at statistically different frequencies between the two cohorts [43]. These findings may be in part responsible for the variation in response to chemotherapy observed in patients with mucinous and non-mucinous CRC.

\section{Radiotherapy Resistance in Mucinous Colorectal Cancer}

A meta-analysis of response to neoadjuvant chemoradiotherapy in mucinous and non-mucinous rectal cancers has identified lower rates of pathological complete response and tumor downstaging in mucinous cases [70]. In addition, a multivariate analysis by Shin et al. indicated that mucinous rectal cancer was a negative prognostic factor for survival following NACRT in rectal cancer [71]. In contrast, analysis of data from the Dutch cancer registry and trial cohorts demonstrated that although mucinous cancers were associated with higher rates of positive circumferential margin positivity, no difference was observed in survival between mucinous rectal and non-mucinous rectal cancers treated with short course radiotherapy (SCRT) or NACRT [72]. It was noted that while survival in mucinous rectal cancer was inferior in the years from 1989 to 1998, that survival was equivalent in the years after 1999 [72]. These findings suggest that margin positivity post treatment may have different implications in mucinous rectal cancer. Mucinous tumors present at the margin may be acellular and due to tumor response [52].

Subsequent to this meta-analysis, a review of the US national cancer database was conducted by Kiran et al. to identify predictors of response to NACRT included 13,742 patients with 32\% achieving pCR between 2009-2013. Treatment included NACRT and SCRT. The authors demonstrated that mucinous cases were less likely to achieve pCR [73]. Likewise, Hosseini et al. compared outcomes from 46 mucinous 358 non-mucinous locally advanced rectal cancers undergoing NACRT between 2010-2015. On univariate analysis, mucinous cancer was a poor predictor of PCR [74]. A retrospective review of 151 LARC receiving SCRT by Räsänen et al. indicated increased rates of local recurrence in mucinous rectal cancers [75]. Vernmark et al. specifically studied the impact of SCRT versus NACRT on locally advanced mucinous rectal cancers in a review of 433 patients. NACRT was used more frequently in mucinous rectal cancer compared to non-mucinous rectal cancer. In the mucinous group, no significant differences were found between SCRT and LCRT for survival outcomes [76]. Similarly, a retrospective review by Hammarström found mucinous rectal cancers were more likely to be treated with NACRT or SCRT with additional chemotherapy [77]. There was no difference in $\mathrm{pCR}$ rate observed between mucinous and non-mucinous rectal cancers overall [77]. However, no mucinous rectal cancer receiving SCRT alone achieved $\mathrm{pCR}$, but addition of chemotherapy to SCRT improved the pCR rate [77]. Overall, there appears to be a dearth of prospective data comparing radiotherapy approaches for LARC mucinous rectal cancer with evidence heavily reliant on heterogenous database studies. 


\section{Tumor Immune Microenvironment in Mucinous Colorectal Cancer}

Chemoresistance of mucinous $\mathrm{CRC}$ has been attributed to the abundant extracellular MUC2 protein that may act as a physical barrier to immune infiltration. [29]. Additionally, the mucin layer contains adhesion ligands and suppressive cytokines. This tumor environment may prevent the approach of antigen-presenting cells that are required to initiate an immune response, or effector cells required to kill tumor cells [44]. The immune features of mucinous CRC have been explored to a limited extent in the literature. A study by Tozawa et al. noted peri-tumoral lymphocyte infiltration in just $0-4 \%$ of mucinous CRCs compared to $17 \%$ of non-mucinous CRCs in a sample of 152 CRCs [78]. However, a recent analysis found no difference in the distribution of stromal CD8+ lymphocytes or tumor CD8+ lymphocytes in CRC with mucinous characteristics [79]. High-density macrophages infiltration has been associated with poor prognosis in solid tumors with M2 differentiated macrophages associated with tumor migration, invasion, and attenuated anti-tumor immunity [80]. A meta-analysis of four studies has demonstrated association of pan-macrophage, M1 macrophage and M2 macrophage infiltration with mucinous CRC [80].

Recent studies have raised an interesting question regarding the immune profile of mucinous CRC and the potential for immune checkpoint inhibition as a therapeutic option. Mismatch-repair deficiency predicts the response of solid tumors to immune checkpoint inhibition and is the basis for the approval of immune checkpoint inhibitors for treatment of MSI high metastatic MCRC [81]. MSI or deficient mismatch repair results in high neoantigen load and increased immunogenicity of MSI tumors. Deficient mismatch repair and MSI high tumors cluster into the consensus molecular subtype (CMS) 1 of CRC, described as the immune subtype due to the high infiltration of lymphocytes [82]. Additionally, despite having a proficient mismatch repair system, some CMS1 tumors contain polymerase (POLE) mutations leading to very high tumor mutational burden and are likely to be susceptible to immunotherapy [83]. Khan et al. compared the distribution of CMS subtypes in mucinous versus non-mucinous CRC in a cohort of 608 patients and determine that $34 \%$ of mucinous CRCs were CMS1 subtype compared to $13 \%$ of nonmucinous CRC [84]. A higher rate of MSI was also observed in this analysis, consistent with the existing literature [10]. A recent immunohistochemical analysis of CRC tumors showed significant association between mucinous histology and PD-L1 positivity [85]. Llosa et al. investigated the tumor immune microenvironment of mCRC treated with PD-1 blockade in a clinical trial, comparing tumor characteristics of patients who exhibited clinical benefit with patients exhibiting disease progression. Clinical benefit from PD-1 blockade was predicted by a composite score of high extracellular mucin and increased PD-L1 expression at the invasive front [86]. A number of recent studies, albeit in non-CRC models, demonstrated that the MUC1-cystoplasmic subunit activates PD-L1 expression through NK-KB mediated inflammatory signaling and promotes suppression of the tumor immune microenvironment $[87,88]$. Overall, these findings raise the question of whether ICI may represent a potential treatment option for mucinous CRC given the prevalence of MSI and hypermutation in mucinous CRC.

\section{Clinical Approach to Mucinous Colorectal Cancer}

Surgery a key role in the curative treatment of mucinous CRC. The surgical challenge posed by mucinous tumors is largely restricted to rectal cases due to limited access within the bony pelvis and proximity of adjacent organs. The risk of a positive CRM is higher in mucinous rectal cancer [70], although data do not demonstrate association with increased local recurrence, perhaps due to the presence of acellular mucin rather than tumor cells at the positive margin [70]. Optimizing recognition of a mucinous tumor at preoperative investigations is necessary to plan appropriate neoadjuvant treatment and adequate surgical margins. Surgery according to TME principles or, in advanced cases, beyond the standard TME plane improves chances of obtaining a radical resection in mucinous rectal cancers which are generally larger and less likely to respond to neoadjuvant chemoradiotherapy [72]. Oncological outcomes from open versus laparoscopic resection of 
mucinous CRC has been explored in a single-center setting by Huang et al. who demonstrated oncological safety of laparoscopy in the era of TME surgery [89]. The preoperative histopathological diagnosis of mucinous rectal cancer is known to be challenging with Sengul et al. reporting $80 \%$ of mucinous tumors being missed by biopsy [90]. MRI imaging is diagnostically superior to preoperative biopsy sampling for detection of a mucinous rectal tumor [91]. The characteristic appearance of high signal intensity mucous may be detected using high-resolution T2-weighted MRI and allows accurate differentiation of mucinous and non-mucinous tumors $[29,92]$.

The prognosis of mucinous CRC has been explored in numerous observational studies with mixed results. Overall, the prognostic impact of mucinous CRC appears to be most pronounced in rectal compared to colon cancer and in the metastatic setting. A metaanalysis of 34 studies published in 2012 reported worse OS in mucinous CRC compared to non-mucinous CRC but with significant heterogeneity present in the analysis [93]. Analysis of two large historical databases (SEER 1973-2011, Linköping Cancer Database 1972-2009) published in 2015 demonstrated worse cancer specific survival in mucinous CRC. Multivariate analysis of included cases showed that mucinous status was an independent predictor of poor prognosis in rectal cancer [94]. Most recently, Benesch et al. summarized the clinical, demographic and mortality outcomes from mucinous adenocarcinoma arising in 16 primary sites. Data were derived from the Surveillance, Epidemiology, and End Results Program SEER program, a large US population-level cancer database. The analysis included 448,221 cases of colon cancer (mucinous $=9 \%$ ) and 194,109 cases of rectal cancer (mucinous $=4.6 \%$ ). Worse 5-year and 10-year OS was observed in rectal mucinous cancer when compared to non-mucinous rectal cancer $(5$-year OS $=53.1 \%$ vs. $59.8 \%$; 10 -year OS $=44.1 \%$ vs. $50.7 \%$ ) [95].

\section{Future Perspectives: Targeting Cell Death}

The literature informs us that mucinous CRC is a distinct form of CRC with molecular characteristics that differentiate it from non-mucinous CRC. It appears that the development of mucinous CRC may diverge from the classic chromosomal instability pathway with elements of microsatellite instability prominent in the molecular characteristics of mucinous CRC. Mucinous CRC is capable of evading cell death, firstly through physical barriers to chemotherapy and secondly by molecular mechanisms to inhibit apoptosis and antagonize chemotherapy drug activity. The current literature identifies a number of relevant questions regarding mucinous $\mathrm{CRC}$ and reveals opportunities for future investigation. The interplay between mucinous CRC and the host immune system requires further investigation. Targeted treatment with immune checkpoint inhibitors may be beneficial given the increased association between mucinous tumors and immune checkpoint expression and tumor microenvironment immune suppression. Regular inclusion of extracellular mucin as a variable in chemotherapeutic trials is encouraged to understand the response of mucinous CRC to established and emerging treatments. Although BCL2 inhibitory molecules have had limited effect in preclinical CRC studies due to loss of BCL2 expression [96], emerging BCL- $X_{L}$ inhibitors may represent a targeted approach to mucinous CRC given the increased BCL- $X_{L}$ expression observed in response to MUC1 and MUC5AC overexpression. Pre-clinical data demonstrated the activation of cell survival signaling including Akt and PI3K pathways in response to mucin overexpression. Novel treatment strategies may include inhibition of the PI3K-Akt survival pathway in combination with conventional chemotherapy may impair mucinous cell survival mechanisms. In addition, exploiting MUC2 protein production inherent to mucinous CRC, combination of PI3K-Akt inhibition and induction of ERS stress with molecules such as celecoxib may present a novel strategy to impair MUC2 production, induce ERS stress triggered apoptosis, and prevent cell survival in mucinous CRC. Finally, targeting necroptotic cell death may offer an alternative therapeutic strategy in mucinous tumors with impaired apoptotic pathways. 
Funding: This research was funded by the RCSI StAR MD programme, grant number 19437 and the Beaumont Hospital Colorectal Research Trust, grant number 19518.

Conflicts of Interest: The authors declare no conflict of interest. The funders had no role in the design of the study; in the collection, analyses, or interpretation of data; in the writing of the manuscript, or in the decision to publish the results.

\section{References}

1. Arnold, M.; Sierra, M.S.; Laversanne, M.; Soerjomataram, I.; Jemal, A.; Bray, F. Global patterns and trends in colorectal cancer incidence and mortality. Gut 2016, 66, 683-691. [CrossRef] [PubMed]

2. Nagtegaal, I.D.; Odze, R.D.; Klimstra, D.; Paradis, V.; Rugge, M.; Schirmacher, P.; Washington, M.K.; Carneiro, F.; Cree, I.A.; The WHO Classification of Tumours Editorial Board. The 2019 WHO classification of tumours of the digestive system. Histopathology 2019, 76, 182-188. [CrossRef] [PubMed]

3. Hugen, N.; Verhoeven, R.H.A.; Radema, S.A.; De Hingh, I.H.J.T.; Pruijt, J.F.M.; Nagtegaal, I.D.; Lemmens, V.E.P.P.; De Wilt, J.H.W. Prognosis and value of adjuvant chemotherapy in stage III mucinous colorectal carcinoma. Ann. Oncol. 2013, 24, $2819-2824$. [CrossRef] [PubMed]

4. Hyngstrom, J.R.; Hu, C.-Y.; Xing, Y.; You, Y.N.; Feig, B.W.; Skibber, J.M.; Rodriguez-Bigas, M.A.; Cormier, J.N.; Chang, G.J. Clinicopathology and Outcomes for Mucinous and Signet Ring Colorectal Adenocarcinoma: Analysis from the National Cancer Data Base. Ann. Surg. Oncol. 2012, 19, 2814-2821. [CrossRef]

5. Kang, H.; O'Connell, J.B.; Maggard, M.A.; Sack, J.; Ko, C.Y. A 10-Year Outcomes Evaluation of Mucinous and Signet-Ring Cell Carcinoma of the Colon and Rectum. Dis. Colon Rectum 2005, 48, 1161-1168. [CrossRef]

6. Aust, D.E.; Terdiman, J.P.; Willenbucher, R.F.; Chang, C.G.; Molinaro-Clark, A.; Baretton, G.B.; Loehrs, U.; Waldman, F.M. The APC/?-catenin pathway in ulcerative colitis-related colorectal carcinomas: A mutational analysis. Cancer 2002, 94, $1421-1427$. [CrossRef] [PubMed]

7. Fearon, E.R. Molecular Genetics of Colorectal Cancer. Annu. Rev. Pathol. Mech. Dis. 2011, 6, 479-507. [CrossRef] [PubMed]

8. Boland, C.R.; Goel, A. Microsatellite instability in colorectal cancer. Gastroenterology 2010, 138, 2073-2087. [CrossRef] [PubMed]

9. Grady, W.M.; Carethers, J.M. Genomic and Epigenetic Instability in Colorectal Cancer Pathogenesis. Gastroenterology 2008, 135, 1079-1099. [CrossRef] [PubMed]

10. Reynolds, I.S.; Furney, S.J.; Kay, E.W.; McNamara, D.A.; Prehn, J.H.M.; Burke, J.P. Meta-analysis of the molecular associations of mucinous colorectal cancer. BJS 2019, 106, 682-691. [CrossRef]

11. Luo, C.; Cen, S.; Ding, G.; Wu, W. Mucinous colorectal adenocarcinoma: Clinical pathology and treatment options. Cancer Commun. 2019, 39, 13. [CrossRef]

12. Hugen, N.; Simons, M.; Halilović, A.; Van Der Post, R.S.; Bogers, A.J.; Zanten, M.A.M.-V.; De Wilt, J.H.; Nagtegaal, I.D. The molecular background of mucinous carcinoma beyond MUC2. J. Pathol. Clin. Res. 2014, 1, 3-17. [CrossRef]

13. Morikawa, T.; Kuchiba, A.; Qian, Z.R.; Mino-Kenudson, M.; Hornick, J.L.; Yamauchi, M.; Imamura, Y.; Liao, X.; Nishihara, R.; Meyerhardt, J.A.; et al. Prognostic Significance and Molecular Associations of Tumor Growth Pattern in Colorectal Cancer. Ann. Surg. Oncol. 2011, 19, 1944-1953. [CrossRef]

14. Leystra, A.A.; Deming, D.A.; Zahm, C.D.; Farhoud, M.; Olson, T.J.P.; Hadac, J.N.; Nettekoven, L.A.; Albrecht, D.M.; Clipson, L.; Sullivan, R.; et al. Mice Expressing Activated PI3K Rapidly Develop Advanced Colon Cancer. Cancer Res. 2012, 72, $2931-2936$. [CrossRef]

15. Hugen, N.; Van Beek, J.J.P.; De Wilt, J.H.W.; Nagtegaal, I.D. Insight into Mucinous Colorectal Carcinoma: Clues from Etiology. Ann. Surg. Oncol. 2014, 21, 2963-2970. [CrossRef] [PubMed]

16. Kufe, D.W. Mucins in cancer: Function, prognosis and therapy. Nat. Rev. Cancer 2009, 9, 874-885. [CrossRef] [PubMed]

17. Wang, H.; Jin, S.; Lu, H.; Mi, S.; Shao, W.; Zuo, X.; Yin, H.; Zeng, S.; Shimamoto, F.; Qi, G. Expression of survivin, MUC2 and MUC5 in colorectal cancer and their association with clinicopathological characteristics. Oncol. Lett. 2017, 14, 1011-1016. [CrossRef]

18. Li, L.; Huang, P.-L.; Yu, X.-J.; Bu, X.-D. Clinicopathological significance of mucin 2 immunohistochemical expression in colorectal cancer: A meta-analysis. Chin. J. Cancer Res. 2012, 24, 190-195. [CrossRef] [PubMed]

19. $\mathrm{Bu}, \mathrm{X} .-\mathrm{D}$. Altered expression of MUC2 and MUC5AC in progression of colorectal carcinoma. World J. Gastroenterol. 2010, 16, 4089-4094. [CrossRef] [PubMed]

20. Debunne, H.; Ceelen, W. Mucinous Differentiation in Colorectal Cancer: Molecular, Histological and Clinical Aspects. Acta Chir. Belg. 2013, 113, 385-390. [CrossRef] [PubMed]

21. Losi, L.; Scarselli, A.; Benatti, P.; de Leon, M.P.; Roncucci, L.; Pedroni, M.; Borghi, F.; Lamberti, I.; Rossi, G.; Marino, M.; et al. Relationship between MUC5AC and altered expression of MLH1 protein in mucinous and non-mucinous colorectal carcinomas. Pathol. Res. Pract. 2004, 200, 371-377. [CrossRef]

22. Imai, Y.; Yamagishi, H.; Fukuda, K.; Ono, Y.; Inoue, T.; Ueda, Y. Differential mucin phenotypes and their significance in a variation of colorectal carcinoma. World J. Gastroenterol. 2013, 19, 3957-3968. [CrossRef] [PubMed]

23. Velcich, A.; Yang, W.; Heyer, J.; Fragale, A.; Nicholas, C.; Viani, S.; Kucherlapati, R.; Lipkin, M.; Yang, K.; Augenlicht, L. Colorectal Cancer in Mice Genetically Deficient in the Mucin Muc2. Science 2002, 295, 1726-1729. [CrossRef] [PubMed] 
24. Kim, Y.S.; Okudaira, K.; Kakar, S.; Cun, L.; Choi, E.; DeCamillis, R.W.; Miura, S.; Sleisenger, M.H.; Deng, G.; Kim, Y. MUC2 gene promoter methylation in mucinous and non-mucinous colorectal cancer tissues. Int. J. Oncol. 2010, 36, 765-775. [CrossRef] [PubMed]

25. Byrd, J.C.; Bresalier, R.S. Mucins and mucin binding proteins in colorectal cancer. Cancer Metastasis Rev. 2004, 23, 77-99. [CrossRef] [PubMed]

26. Ookawa, K.; Kudo, T.; Aizawa, S.; Saito, H.; Tsuchida, S. Transcriptional Activation of the MUC2 Gene by p53. J. Biol. Chem. 2002, 277, 48270-48275. [CrossRef] [PubMed]

27. Perrais, M.; Pigny, P.; Copin, M.-C.; Aubert, J.-P.; Van Seuningen, I. Induction of MUC2 and MUC5AC Mucins by Factors of the Epidermal Growth Factor (EGF) Family Is Mediated by EGF Receptor/Ras/Raf/Extracellular Signal-regulated Kinase Cascade and Sp1. J. Biol. Chem. 2002, 277, 32258-32267. [CrossRef] [PubMed]

28. Dilly, A.K.; Song, X.; Zeh, H.J.; Guo, Z.S.; Lee, Y.J.; Bartlett, D.L.; Choudry, H.A. Mitogen-activated protein kinase inhibition reduces mucin 2 production and mucinous tumor growth. Transl. Res. 2015, 166, 344-354. [CrossRef] [PubMed]

29. Hugen, N.; Brown, G.; Glynne-Jones, R.; De Wilt, J.H.W.; Nagtegaal, I.D. Advances in the care of patients with mucinous colorectal cancer. Nat. Rev. Clin. Oncol. 2015, 13, 361-369. [CrossRef] [PubMed]

30. Green, D.R. Cell Death: Apoptosis and Other Means to an End; Cold Spring Harbor Laboratory Press: New York, NY, USA, 2018.

31. Chand, H.S.; Montano, G.; Huang, X.; Randell, S.H.; Mebratu, Y.; Petersen, H.; Tesfaigzi, Y. A genetic variant of p53 restricts the mucous secretory phenotype by regulating SPDEF and Bcl-2 expression. Nat. Commun. 2014, 5, 5567. [CrossRef]

32. Contu, P.C.; Contu, S.S.; Moreira, L.F. Bcl-2 expression in rectal cancer. Arq. Gastroenterol. 2006, 43, 284-287. [CrossRef]

33. Patankar, J.V.; Becker, C. Cell death in the gut epithelium and implications for chronic inflammation. Nat. Rev. Gastroenterol. Hepatol. 2020, 17, 543-556. [CrossRef] [PubMed]

34. Ren, J.; Agata, N.; Chen, D.; Li, Y.; Yu, W.-H.; Huang, L.; Raina, D.; Chen, W.; Kharbanda, S.; Kufe, D. Human MUC1 carcinomaassociated protein confers resistance to genotoxic anticancer agents. Cancer Cell 2004, 5, 163-175. [CrossRef]

35. Agata, N.; Ahmad, R.; Kawano, T.; Raina, D.; Kharbanda, S.; Kufe, D. MUC1 Oncoprotein Blocks Death Receptor-Mediated Apoptosis by Inhibiting Recruitment of Caspase-8. Cancer Res. 2008, 68, 6136-6144. [CrossRef] [PubMed]

36. Sheehan, K.M.; O’Donovan, D.G.; Fitzmaurice, G.; O’Grady, A.; O’Donoghue, D.P.; Sheahan, K.; Byrne, M.F.; Conroy, R.M.; Kay, E.W.; Murray, F.E. Prognostic relevance of Fas (APO-1/CD95) ligand in human colorectal cancer. Eur. J. Gastroenterol. Hepatol. 2003, 15, 375-380. [CrossRef]

37. Chen, Q.; Li, D.; Ren, J.; Li, C.; Xiao, Z.-X. MUC1 activates JNK1 and inhibits apoptosis under genotoxic stress. Biochem. Biophys. Res. Commun. 2013, 440, 179-183. [CrossRef]

38. Gupta, B.K.; Maher, D.M.; Ebeling, M.C.; Stephenson, P.D.; Puumala, S.E.; Koch, M.R.; Aburatani, H.; Jaggi, M.; Chauhan, S.C. Functions and regulation of MUC13 mucin in colon cancer cells. J. Gastroenterol. 2013, 49, 1378-1391. [CrossRef] [PubMed]

39. Sheng, Y.H.; Lourie, R.; Lindén, S.K.; Jeffery, P.L.; Roche, D.; Tran, T.V.; Png, C.W.; Waterhouse, N.; Sutton, P.; Florin, T.H.J.; et al. The MUC13 cell-surface mucin protects against intestinal inflammation by inhibiting epithelial cell apoptosis. Gut 2011, 60, 1661-1670. [CrossRef] [PubMed]

40. Ramesh, P.; Medema, J.P. BCL-2 family deregulation in colorectal cancer: Potential for BH3 mimetics in therapy. Apoptosis 2020, 25, 305-320. [CrossRef] [PubMed]

41. Zhang, H.; Evertsson, S.; Sun, X. Clinicopathological and genetic characteristics of mucinous carcinomas in the colorectum. Int. J. Oncol. 1999, 14. [CrossRef] [PubMed]

42. Glasgow, S.C.; Yu, J.; Carvalho, L.P.; Shannon, W.D.; Fleshman, J.W.; McLeod, H.L. Unfavourable expression of pharmacologic markers in mucinous colorectal cancer. Br. J. Cancer 2005, 92, 259-264. [CrossRef] [PubMed]

43. Reynolds, I.S.; O'Connell, E.; Fichtner, M.; McNamara, D.A.; Kay, E.W.; Prehn, J.H.M.; Furney, S.J.; Burke, J.P. Mucinous adenocarcinoma is a pharmacogenomically distinct subtype of colorectal cancer. Pharmacogenomics J. 2019, 20, 524-532. [CrossRef] [PubMed]

44. Johansson, M.E.V.; Hansson, M.E.V.J.G.C. Immunological aspects of intestinal mucus and mucins. Nat. Rev. Immunol. 2016, 16, 639-649. [CrossRef] [PubMed]

45. De Campos-Lobato, L.F.; Dietz, D.W.; Stocchi, L.; Vogel, J.D.; Lavery, I.C.; Goldblum, J.R.; Skacel, M.; Pelley, R.J.; Kalady, M.F. Clinical implications of acellular mucin pools in resected rectal cancer with pathological complete response to neoadjuvant chemoradiation1. Colorectal Dis. 2010, 14, 62-67. [CrossRef]

46. Smith, K.D.; Tan, D.; Das, P.; Chang, G.J.; Kattepogu, K.; Feig, B.W.; Skibber, J.M.; Rodriguez-Bigas, M.A. Clinical Significance of Acellular Mucin in Rectal Adenocarcinoma Patients With a Pathologic Complete Response to Preoperative Chemoradiation. Ann. Surg. 2010, 251, 261-264. [CrossRef]

47. Bhatti, A.B.H.; Akbar, A.; Khattak, S.; Kazmi, A.S.; Jamshed, A.; Syed, A.A. Impact of acellular mucin pools on survival in patients with complete pathological response to neoadjuvant treatment in rectal cancer. Int. J. Surg. 2014, 12, 1123-1126. [CrossRef]

48. Lim, S.-B.; Hong, S.-M.; Yu, C.S.; Hong, Y.S.; Kim, T.W.; Park, J.-H.; Kim, J.H.; Kim, J.C. Prevalence and Clinical Significance of Acellular Mucin in Locally Advanced Rectal Cancer Patients Showing Pathologic Complete Response to Preoperative Chemoradiotherapy. Am. J. Surg. Pathol. 2013, 37, 47-52. [CrossRef] [PubMed]

49. Reynolds, I.S.; McNamara, D.A.; Kay, E.W.; O’Neill, B.; Deasy, J.; Burke, J.P. The significance of mucin pools following neoadjuvant chemoradiotherapy for locally advanced rectal cancer. J. Surg. Oncol. 2018, 118, 1129-1134. [CrossRef] [PubMed] 
50. Sun, Y.; Wu, X.; Zhang, Y.; Lin, H.; Lu, X.; Huang, Y.; Chi, P. Pathological complete response may underestimate distant metastasis in locally advanced rectal cancer following neoadjuvant chemoradiotherapy and radical surgery: Incidence, metastatic pattern, and risk factors. Eur. J. Surg. Oncol. 2019, 45, 1225-1231. [CrossRef] [PubMed]

51. Zhang, L.; Guan, H.; Luo, Q.; Yuan, L.; Mao, Y.; Wu, X.; Pan, Z.; Lin, J.; Peng, J. Prognostic impact of acellular mucin pools towards the patients with locally advanced rectal cancer achieving pathological complete response after preoperative chemoradiotherapy. Ther. Adv. Gastroenterol. 2020, 13. [CrossRef]

52. Amin, M.B.; Edge, S.; Greene, F.; Byrd, D.R.; Brookland, R.K.; Washington, M.K.; Gershenwald, J.E.; Compton, C.C.; Hess, K.R.; Sullivan, D.C.; et al. AJCC Cancer Staging Manual, 8th ed.; Springer: New York, NY, USA, 2017; pp. $252-254$.

53. Maji, S.; Panda, S.; Samal, S.K.; Shriwas, O.; Rath, R.; Pellecchia, M.; Emdad, L.; Das, S.K.; Fisher, P.B.; Dash, R. Bcl-2 Antiapoptotic Family Proteins and Chemoresistance in Cancer. Adv. Cancer Res. 2018, 137, 37-75. [CrossRef]

54. Mardi, K.; Bhardwaj, M.; Kaushal, V.; Sharma, M.; Rao, M. Bcl-2 expression in colorectal carcinoma and its correlation with clinicopathological parameters. Clin. Cancer Investig. J. 2020, 9, 182. [CrossRef]

55. Miquel, C.; Borrini, F.; Grandjouan, S.; Aupérin, A.; Viguier, J.; Velasco, V.; Duvillard, P.; Praz, F.; Sabourin, J.-C. Role of bax Mutations in Apoptosis in Colorectal Cancers With Microsatellite Instability. Am. J. Clin. Pathol. 2005, 123, 562-570. [CrossRef] [PubMed]

56. Myung, D.-S.; Park, Y.-L.; Chung, C.-Y.; Park, H.-C.; Kim, J.-S.; Cho, S.-B.; Lee, W.-S.; Lee, K.-H.; Lee, J.-H.; Joo, Y.-E. Expression of Livin in Colorectal Cancer and Its Relationship to Tumor Cell Behavior and Prognosis. PLoS ONE 2013, 8, e73262. [CrossRef]

57. Faruk, M.; Ibrahim, S.; Aminu, S.M.; Adamu, A.; Abdullahi, A.; Suleiman, A.M.; Rafindadi, A.H.; Mohammed, A.; Iliyasu, Y.; Idoko, J.; et al. Prognostic significance of BIRC7/Livin, Bcl-2, p53, Annexin V, PD-L1, DARC, MSH2 and PMS2 in colorectal cancer treated with FOLFOX chemotherapy with or without aspirin. PLoS ONE 2021, 16, e0245581. [CrossRef] [PubMed]

58. Raina, D.; Kharbanda, S.; Kufe, D. The MUC1 Oncoprotein Activates the Anti-apoptotic Phosphoinositide 3-Kinase/Akt and Bcl-xL Pathways in Rat 3 Y1 Fibroblasts. J. Biol. Chem. 2004, 279, 20607-20612. [CrossRef]

59. Koornstra, J.J.; Jalving, M.; Rijcken, F.E.; Westra, J.; Zwart, N.; Hollema, H.; De Vries, E.G.; Hofstra, R.W.; Plukker, J.T.; De Jong, S.; et al. Expression of tumour necrosis factor-related apoptosis-inducing ligand death receptors in sporadic and hereditary colorectal tumours: Potential targets for apoptosis induction. Eur. J. Cancer 2005, 41, 1195-1202. [CrossRef]

60. Dilly, A.K.; Honick, B.D.; Lee, Y.J.; Guo, Z.S.; Zeh, H.J.; Bartlett, D.L.; Choudry, H.A. Targeting G-protein coupled receptor-related signaling pathway in a murine xenograft model of appendiceal pseudomyxoma peritonei. Oncotarget 2017, 8, 106888-106900. [CrossRef] [PubMed]

61. Dilly, A.K.; Honick, B.D.; Lee, Y.J.; Bartlett, D.L.; Choudry, H.A. Synergistic apoptosis following endoplasmic reticulum stress aggravation in mucinous colon cancer. Orphanet J. Rare Dis. 2020, 15, 1-13. [CrossRef] [PubMed]

62. Chong, W.C.; Shastri, M.D.; Eri, R. Endoplasmic Reticulum Stress and Oxidative Stress: A Vicious Nexus Implicated in Bowel Disease Pathophysiology. Int. J. Mol. Sci. 2017, 18, 771. [CrossRef] [PubMed]

63. Darling, N.J.; Cook, S.J. The role of MAPK signalling pathways in the response to endoplasmic reticulum stress. Biochim. Biophys. Acta 2014, 1843, 2150-2163. [CrossRef] [PubMed]

64. Dilly, A.; Honick, B.D.; Lee, Y.J.; Bartlett, D.L.; Choudry, H.A. Rational application of targeted therapeutics in mucinous colon/appendix cancers with positive predictive factors. Cancer Med. 2020, 9, 1753-1767. [CrossRef]

65. Zhu, X.; Long, X.; Luo, X.; Song, Z.; Li, S.; Wang, H. Abrogation of MUC5AC Expression Contributes to the Apoptosis and Cell Cycle Arrest of Colon Cancer Cells. Cancer Biother. Radiopharm. 2016, 31, 261-267. [CrossRef]

66. Pothuraju, R.; Rachagani, S.; Krishn, S.R.; Chaudhary, S.; Nimmakayala, R.K.; Siddiqui, J.A.; Ganguly, K.; Lakshmanan, I.; Cox, J.L.; Mallya, K.; et al. Molecular implications of MUC5AC-CD44 axis in colorectal cancer progression and chemoresistance. Mol. Cancer 2020, 19, 1-14. [CrossRef] [PubMed]

67. Nam, K.; Oh, S.; Lee, K.-M.; Yoo, S.-A.; Shin, I. CD44 regulates cell proliferation, migration, and invasion via modulation of c-Src transcription in human breast cancer cells. Cell. Signal. 2015, 27, 1882-1894. [CrossRef] [PubMed]

68. Sheng, Y.H.; He, Y.; Hasnain, S.Z.; Wang, R.; Tong, H.; Clarke, D.T.; Lourie, R.; Oancea, I.; Wong, K.Y.; Lumley, J.W.; et al. MUC13 protects colorectal cancer cells from death by activating the NF- $\mathrm{BB}$ pathway and is a potential therapeutic target. Oncogene 2016, 36, 700-713. [CrossRef]

69. Evertsson, S.; Sun, X.F. Protein expression of NF-kappaB in human colorectal adenocarcinoma. Int. J. Mol. Med. 2002, 10, 547-550.

70. McCawley, N.; Clancy, C.; O’Neill, B.D.P.; Deasy, J.; McNamara, D.A.; Burke, J.P. Mucinous Rectal Adenocarcinoma Is Associated with a Poor Response to Neoadjuvant Chemoradiotherapy: A Systematic Review and Meta-analysis. Dis. Colon Rectum 2016, 59, 1200-1208. [CrossRef] [PubMed]

71. Shin, U.S.; Yu, C.S.; Kim, J.H.; Kim, T.W.; Lim, S.-B.; Yoon, S.N.; Yoon, Y.S.; Kim, C.W.; Kim, J.C. Mucinous Rectal Cancer: Effectiveness of Preoperative Chemoradiotherapy and Prognosis. Ann. Surg. Oncol. 2011, 18, 2232-2239. [CrossRef] [PubMed]

72. Hugen, N.; Van De Velde, C.J.; Bosch, S.L.; Fütterer, J.J.; Elferink, M.A.; Marijnen, C.A.; Rutten, H.J.; De Wilt, J.H.; Nagtegaal, I.D. Modern Treatment of Rectal Cancer Closes the Gap Between Common Adenocarcinoma and Mucinous Carcinoma. Ann. Surg. Oncol. 2015, 22, 2669-2676. [CrossRef] [PubMed]

73. Gash, K.; Baser, O.; Kiran, R. Factors associated with degree of tumour response to neo-adjuvant radiotherapy in rectal cancer and subsequent corresponding outcomes. Eur. J. Surg. Oncol. 2017, 43, 2052-2059. [CrossRef] [PubMed] 
74. Hosseini, S.; Nguyen, N.; Mohammadianpanah, M.; Mirzaei, S.; Bananzadeh, A.M. Predictive Significance of Mucinous Histology on Pathologic Complete Response Rate Following Capecitabine-Based Neoadjuvant Chemoradiation in Rectal Cancer: A Comparative Study. J. Gastrointest. Cancer 2018, 50, 716-722. [CrossRef] [PubMed]

75. Räsänen, M.; Renkonen-Sinisalo, L.; Mustonen, H.; Lepistö, A. Is there a need for neoadjuvant short-course radiotherapy in T3 rectal cancer with positive lymph node involvement? A single-center retrospective cohort study. World J. Surg. Oncol. 2019, 17, 1-7. [CrossRef] [PubMed]

76. Vernmark, K.; Sun, X.-F.; Holmqvist, A. Mucinous and Non-Mucinous Rectal Adenocarcinoma-Differences in Treatment Response to Preoperative Radiotherapy. J. Personal. Med. 2020, 10, 226. [CrossRef] [PubMed]

77. Hammarström, K.; Imam, I.; Mezheyeuski, A.; Ekström, J.; Sjöblom, T.; Glimelius, B. A Comprehensive Evaluation of Associations Between Routinely Collected Staging Information and The Response to (Chemo) Radiotherapy in Rectal Cancer. Cancers 2020, 13, 16. [CrossRef]

78. Tozawa, E.; Ajioka, Y.; Watanabe, H.; Nishikura, K.; Mukai, G.; Suda, T.; Kanoh, T.; Hatakeyama, K. Mucin expression, p53 overexpression, and peritumoral lymphocytic infiltration of advanced colorectal carcinoma with mucus component: Is mucinous carcinoma a distinct histological entity? Pathol. Res. Pract. 2007, 203, 567-574. [CrossRef]

79. Nazemalhosseini-Mojarad, E.; Mohammadpour, S.; Esafahani, A.T.; Gharib, E.; Larki, P.; Moradi, A.; Porhoseingholi, M.A.; Aghdaei, H.A.; Kuppen, P.J.K.; Zali, M.R. Intratumoral infiltrating lymphocytes correlate with improved survival in colorectal cancer patients: Independent of oncogenetic features. J. Cell. Physiol. 2018, 234, 4768-4777. [CrossRef]

80. Zhao, Y.; Ge, X.; Xu, X.; Yu, S.; Wang, J.; Sun, L. Prognostic value and clinicopathological roles of phenotypes of tumour-associated macrophages in colorectal cancer. J. Cancer Res. Clin. Oncol. 2019, 145, 3005-3019. [CrossRef]

81. Le, D.T.; Uram, J.N.; Wang, H.; Bartlett, B.R.; Kemberling, H.; Eyring, A.D.; Skora, A.D.; Luber, B.S.; Azad, N.S.; Laheru, D.; et al. PD-1 Blockade in Tumors with Mismatch-Repair Deficiency. N. Engl. J. Med. 2015, 372, 2509-2520. [CrossRef]

82. Guinney, J.; Dienstmann, R.; Wang, X.; De Reyniès, A.; Schlicker, A.; Soneson, C.; Marisa, L.; Roepman, P.; Nyamundanda, G.; Angelino, P.; et al. The consensus molecular subtypes of colorectal cancer. Nat. Med. 2015, 21, 1350-1356. [CrossRef]

83. Gong, J.; Wang, C.; Lee, P.P.; Chu, P.; Fakih, M. Response to PD-1 Blockade in Microsatellite Stable Metastatic Colorectal Cancer Harboring aPOLEMutation. J. Natl. Compr. Cancer Netw. 2017, 15, 142-147. [CrossRef]

84. Khan, M.; Loree, J.M.; Advani, S.M.; Ning, J.; Li, W.; Pereira, A.; Lam, M.; Raghav, K.; Morris, V.K.; Broaddus, R.; et al. Prognostic Implications of Mucinous Differentiation in Metastatic Colorectal Carcinoma Can Be Explained by Distinct Molecular and Clinicopathologic Characteristics. Clin. Colorectal. Cancer 2018, 17, e699-e709. [CrossRef]

85. Jung, D.H.; Park, H.J.; Jang, H.H.; Kim, S.-H.; Jung, Y.; Lee, W.-S. Clinical Impact of PD-L1 Expression for Survival in Curatively Resected Colon Cancer. Cancer Investig. 2020, 38, 406-414. [CrossRef] [PubMed]

86. Llosa, N.J.; Luber, B.; Siegel, N.; Awan, A.H.; Oke, T.; Zhu, Q.; Bartlett, B.R.; Aulakh, L.K.; Thompson, E.D.; Jaffee, E.M.; et al. Immunopathologic Stratification of Colorectal Cancer for Checkpoint Blockade Immunotherapy. Cancer Immunol. Res. 2019, 7 , 1574-1579. [CrossRef] [PubMed]

87. Bouillez, A.; Rajabi, H.; Jin, C.; Samur, M.; Tagde, A.; Alam, M.; Hiraki, M.; Maeda, T.; Hu, X.; Adeegbe, D.; et al. MUC1-C integrates PD-L1 induction with repression of immune effectors in non-small-cell lung cancer. Oncogene 2017, 36, 4037-4046. [CrossRef] [PubMed]

88. Bouillez, A.; Adeegbe, D.; Jin, C.; Hu, X.; Tagde, A.; Alam, M.; Rajabi, H.; Wong, K.-K.; Kufe, D. MUC1-C promotes the suppressive immune microenvironment in non-small cell lung cancer. OncoImmunology 2017, 6, e1338998. [CrossRef] [PubMed]

89. Huang, Q.; Zou, M.-H.; Jiang, Y.; Chen, Z.-P.; Wang, Q.; Wei, J.-C.; Li, W.-L.; Cao, J. Outcomes of Laparoscopic Surgery for Mucinous Colorectal Adenocarcinoma. J. Laparoendosc. Adv. Surg. Tech. 2020. [CrossRef] [PubMed]

90. Sengul, N.; Wexner, S.D.; Woodhouse, S.; Arrigain, S.; Xu, M.; Larach, J.A.; Ahn, B.K.; Weiss, E.G.; Nogueras, J.J.; Berho, M. Effects of radiotherapy on different histopathological types of rectal carcinoma. Colorectal. Dis. 2006, 8, 283-288. [CrossRef]

91. Yu, S.K.; Chand, M.; Tait, D.M.; Brown, G. Magnetic resonance imaging defined mucinous rectal carcinoma is an independent imaging biomarker for poor prognosis and poor response to preoperative chemoradiotherapy. Eur. J. Cancer 2014, 50, 920-927. [CrossRef] [PubMed]

92. Kim, M.-J.; Park, J.S.; Park, S.I.; Kim, N.K.; Kim, J.H.; Moon, H.J.; Park, Y.N.; Kim, W.H. Accuracy in Differentiation of Mucinous and Nonmucinous Rectal Carcinoma on MR Imaging. J. Comput. Assist. Tomogr. 2003, 27, 48-55. [CrossRef] [PubMed]

93. Verhulst, J.; Ferdinande, L.; Demetter, P.; Ceelen, W. Mucinous subtype as prognostic factor in colorectal cancer: A systematic review and meta-analysis. J. Clin. Pathol. 2012, 65, 381-388. [CrossRef] [PubMed]

94. Wang, M.-J.; Ping, J.; Li, Y.; Holmqvist, A.; Adell, G.; Arbman, G.; Zhang, H.; Zhou, Z.-G.; Sun, X.-F. Prognostic Significance and Molecular Features of Colorectal Mucinous Adenocarcinomas: A Strobe-Compliant Study. Medicine 2015, 94, e2350. [CrossRef] [PubMed]

95. Benesch, M.G.K.; Mathieson, A. Epidemiology of Mucinous Adenocarcinomas. Cancers 2020, 12, 3193. [CrossRef] [PubMed]

96. Soderquist, R.S.; Crawford, L.; Liu, E.; Lu, M.; Agarwal, A.; Anderson, G.R.; Lin, K.H.; Winter, P.S.; Cakir, M.; Wood, K.C. Systematic mapping of BCL-2 gene dependencies in cancer reveals molecular determinants of BH3 mimetic sensitivity. Nat. Commun. 2018, 9, 1-13. [CrossRef] 